\title{
O Instituto Interamericano de Direito de Autor (IIDA).
}

\author{
Antônio Chaves \\ Catedrático de Direito Civil na Faculdade de Direito \\ da Universidade de São Paulo e Presidente do \\ Instituto Interamericano de Direito do Autor.
}

\section{A Batalha em prol do direito de autor.}

Não existe atividade mais nobre do que a intelectual: suas manifestações, artística, literária ou científica, sobrepairam qualquer outra com vôos de condor.

Desde as obras musicais, as únicas que, numa linguagem universal, conseguem aproximar e harmonizar os homens de todas as crenças, e de todas as opiniões, desde as contribuições dos maiores pensadores - pedras miliares no caminho da civilização, que muitas vezes abalam em profundidade, destruindo velhas construções para permitir a edificação de novas, - até os escritos em que os cientistas descrevem suas descobertas, o resultado de decênios de pesquisas ou indicam rumos destinados a desvendar mistérios, a descobrir mundos, a aliviar padecimentos de milhões de criaturas, não há exagero em dizer que mais ainda do que a oração, é a produção intelectual que aproxima o homem ao Criador.

*. Oração de abertura do $\mathrm{X}$ Congresso Internacional sobre Direitos do Autor, realizado em Brasília, no dia 29.10.1973, no Auditório Nereu Ramos, da Câmara dos Deputados. 
Parece, portanto, mais do que lógico, necessário, que nenhuma outra atividade humana receba maior desvelo, mais acendrado carinho por parte do legislador.

Que decepção, no entanto, seja no âmbito nacional, como no internacional!

Enquanto que no mundo inteiro a aquisição e a transmissão da posse e da propriedade de bens materiais está minuciosamente regulada, enquanto que as demais atividades profissionais se sentem protegidas, e os próprios trabalhadores manuais da cidade e do campo vão conseguindo um status condigno, é desolador o panorama que se descortina no tocante à proteção da propriedade intelectual.

Não conhecem, em geral, os legisladores, em todos os países, as minúcias e a delicada contextura do Direito de Autor, não percebem a urgência com que precisa ser amparado, não a título de favor, mas no interesse de todos, justamente na sua condição de criador, isto é, fonte primária de quaisquer outras prerrogativas.

Não lhe dispensam, por isso, o apoio de que necessita na luta que trava, de um lado, contra os empresários e industriais, que sob os mais diversificados pretextos, persistem em obter, por meio de cessões, fatias cada vez mais amplas de seus privilégios tão limitados, e de outro, contra os usuários, que querem aproveitar mais e mais suas obras, retribuindo-as menos e menos.

Em geral tímido, quasi sempre desligado, absorvido por um trabalho que não lhe dá quietação nem tréguas para convívios, muito menos para convívios interesseiros, incapaz de exercer pressões sobre quem quer que seja, sua voz, de tão fraca, perde-se na maré magna da agitação e do clamor das reivindicações e das exigências contingentes dos outros, no tropel de todos aqueles que, tendo embora interesses apenas derivados da sua obra, sabem exigir, sabem reivindicar, sabem impor. 
Afirmar que reina a mais completa, opressiva e preocupadora escuridão em torno do Autor e dos seus direitos, no âmbito interno de cada país não é mera figura retórica.

Quando isso não bastasse, a obra intelectual, infensa por natureza a limitações, a barreiras, a obstáculos, tende a penetrar por toda parte e a expandir-se pelo mundo inteiro.

A mais perfeita das legislações internas será improfícua se não encontrar complementos e expedientes que evitem que a produção intelectual se torne fácil presa, além fronteira, de indivíduos pouco escrupulosos.

Quais os meios, se não para resolver, pelo menos para encaminhar a solução dessas questões angustiantes, apenas algumas, dentre as muitas, das mais complexas?

Devemos partir da verificação singela de que o problema, no seu conjunto, é por demais vasto para que possa ser enfrentado por uma só Nação.

As grandes batalhas vencem-se através de seu parcelamento setorial, e se desistirmos da utopia de querer abraçar o mundo inteiro, reconhecendo, ao mesmo tempo, que a situação está perfeitamente amadurecida para uma solução no âmibto continental, teremos dado o enquadramento acertado.

O primeiro combate já nos brindou com importante vitória, a criação de um centro de informações, documentação e assessoramento, destinado a facilitar e a auxiliar todos os interessados no intercâmbio de idéias, de pesquisas, de publicações, na redação de contratos, de estatutos e regulamentos de sociedade e de entidades, até mesmo de planos e projetos de reformas legislativas, de tudo quanto, enfim, de qualquer modo se refira ou afete o Direito de Autor, promovendo a base necessária para o cadastramento, a divulgação, e, finalmente, a proteção efetiva, melhorando, unificando e potenciando, em nosso Continente, os seus meios de defesa : o 
Institute interamericano de direito de autor.

Como surgiu a idéia?

Percebendo que na Europa a matéria está devidamente regulamentada, sendo satisfatórios os resultados práticos alcançados, que a programação de qualquer tentativa devia encontrar, nas três Américas, a limitação natural decorrente da sua própria expressão geográfica, o que simplificaria e racionalizaria a solução do problema, sem dar-lhe fantasiosas dimensões universalistas, dois especialistas de renome internacional Stephen Ladas e Natalio ChediaK, logo na Primeira Conferência celebrada pela Federação Interamericana de Advogados (FIA), nos idos de 1941, apresentaram um projeto de resolução

"sobre a criação de uma Associação Interamericana da Propriedade Intelectual, consagrada ao estudo comparativo das leis das Repúblicas Americanas, com o propósito de harmonizá-las e de adotar soluções gerais com relação aos problemas da propriedade intelectual interamericana."

Somente decorridos 32 anos, em data de 21.08.1973, por ocasião do xvıır Congresso da mesma Federação, reunido no Rio de Janeiro, é que semelhante ideal foi concretizado, criando-se, finalmente, o marco inicial de uma nova fase dessa especialidade nas Americas: o referido Instituto, associação internacional de natureza privada, sem fim lucrativo, tendo por objeto incrementar o estudo e progresso da proteção efetiva do Direito de Autor na América, coordenando os esforcos dos especialistas e das entidades desejosas de contribuir para a melhor defesa dessas prerrogativas.

Para dizer das razões de caráter social, político e juridico que levaram à sua constituição, e das suas finalidades, nenhuma oportunidade melhor do que esta, do $\mathrm{X}$ Congresso 
Interamericano de Direito Autoral, promovido pela veterana Sociedade Brasileira de Autores Teatrais (sbat), pelo seu Diretor DANiel Rocha, incançável paladino de tantas batalhas, em nome do Presidente do Conselho Panamericano da cisac, Roberto Talice, e nenhum local mais adequado do que Brasília, coração do Brasil, neste augusto salão do Congresso Nacional.

\section{Razões de caráter social.}

A evolução do Direito, que ia se processando lentamente através dos séculos, passou a operar-se agora no decorrer de poucos anos. De decênio em decênio percebe-se a transformação de institutos tradicionais e aparentemente inalteráveis, como o da propriedade, sofrendo hoje em dia tais e tantas restrições que mal a reconheceria um redivivo Papiniano.

Não pode surpreender, nestas condições, que um direito novo surja desde logo marcado pelo sinal dos tempos.

E o que acontece com o Direito de Autor, assinalado por uma série de limitações que bem revelam a marca da socialização, sofrendo diariamente renovadas investidas, a pretexto do barateamento da multiplicação dos exemplares e para divulgação das obras, sob desculpa de maiores facilidades no seu aproveitamento, sob invocação de razões de cultura que não podem ser pleiteadas a custa exclusiva dos autores e dos artistas.

A persistir semelhante mentalidade, não tardarão eles a se considerarem completamente desestimulados, procurando em outros âmbitos que não os de sua predileção, meios para satiasfzer as mais elementares exigências de sobrevivência.

Quando isso não bastasse, por uma deturpação a que se presta por sua natureza imaterial, o Direito de Autor é 
pouco compreendido pelo público em geral, e até mesmo por muitos autores e artistas, que não sabem defendê-lo convenientemente.

Só mediante uma ampla e persistente campanha de informação e esclarecimento será possível alcançar-se algum exito.

\section{Razões de caráter político.}

também não faltavam à criação desse organismo de âmbito continental.

Se o Direito de Autor, por sua própria natureza não tolera fronteiras geográficas ou ideológicas, por que não transformarmos essa característica numa força para conduzí-lo, não no plano nacional, mas no continental, no sentido do seu aperfeiçoamento em todos os países da América?

Trinta leis diferentes, não podem ser todas ótimas!

Procuremos então, sem preocupações de caráter regional, os melhores dispositivos de todas elas, verifiquemos qual o sistema mais racional, elaboremos outros, quando necessário, tracemos aquele modelo que, por mais encariçados que sejam os interesses e as resistências, há de prevalecer um dia em suas linhas essenciais, sem prejuízo do respeito às peculiaridades e às tradições de cada povo!

Encontramo-nos num momento e numa situação privilegiados, num continente em que, realmente, tudo nos une e nada nos separa: semelhança de línguas, de aspirações, de sentimento de fraternidade, de amor à paz, ansiando todos estes povos indómitos por uma emancipação não apenas econômica, mas também cultural.

Por que é que havemos de continuar palmilhando caminhos separados, quando podemos unir nossos esforços e seguir uma só trilha, quando podemos ser companheiros da mesma jornada? 
Que melhor razão política poderia haver do que um perfeito, mútuo, completo entendimento nas medidas a serem então oferecidas com tal força persuasiva que não poderão deixar de ser mais cedo ou mais tarde acatadas pelos governos mais renitentes?

\section{Razões de natureza jurídica.}

São as que mais sobram para a realização de um empreendimento dessa natureza.

o Direito de Autor passa atualmente por uma verdadeira crise de crescimento. Embora em evolução rápida, em franca expansão, mal consegue acompanhar e adaptar-se aos progressos da técnica.

Cada novo sistema de gravação, projeção e aproveitamento da obra: transmissão por meio de satélites artificiais, retransmissão de televisão por cabo, multiplicação por xerox, cassetes, video-cassetes, etc., exige novos métodos de proteção e de cobrança, sob pena de assistirmos ao seu fatal naufrágio.

Tanto no âmbito interno, como na esfera internacional, teve oportunidade de encarecer Natalio ChediaK, no número de 1973 da Revista Mexicana de la Propiedad Industrial y Artistica, é sempre a legislação comparada, não como obra mecânica, mas como elaboração científica, a única que pode demonstrar a quantidade e a qualidade dos impedimentos que se apresentem e preparar o caminho para as fórmulas de conciliação.

Foi dentro desse espírito que a xviII Conferência da Federação Interamericana de Advogados aprovou uma recomendação a ser feita pelo seu secretário-geral, a todos os reitores das universidades do Continente para que se inclua no currículo das escolas de Direito a nossa disciplina ou se promovam cursos de divulgação e de atualização nesse campo. 
Poderá o Instituto, no decurso de poucos anos, reunir um acervo prodigioso de informações jurídicas, técnicas, especulativas, que por sua vez fará refluir, sangue generoso propelido por um coração forte, a legisladores, governantes, administradores de sociedades arrecadadoras, advogados, editores, jornalistas, teatrólogos, cinegrafistas, gravadores, a qualquer interessado, enfim, por motivos de profissão, de estudo, ou de cultura.

\section{As finalidades do instituto.}

Estão indicadas no seu regulamento:

1. Coordenar, melhorar e unificar a proteção efetiva do Direito de Autor, por todos os meios ao seu alcance, e mobilizar, por si ou junto com outros organismos, os meios de defesa de tal Direito.

2. Fomentar o estudo e progresso da proteção do Direito de Autor e Direitos Conexos, facilitando o exame profundo e imparcial das questões que afetem ao Direito de Autor interamericano, inclusive a intensificação destes estudos nas Universidades da América.

3. Esforçar-se no sentido de que os países americanos outorguem a mais ampla proteção ao Direito de Autor e estimular o desenvolvimento e aplicação das convenções internacionais vigentes.

4. Prestar sua cooperação como órgão técnico de consulta e de planejamento a pessoas naturais e jurídicas de Direito Público ou Privado, inclusive internacionais, que lhe solicitem uma opinião consultiva ou sua mediação por qualquer forma.

5. Criar e manter um "Centro Interamericano" de informação, documentação e assessoramento, que facilite a todos os membros o exame das reformas projetadas e/ou aprovadas em qualquer país da América que se refiram ou 
de qualquer modo afetem o estado atual das leis sobre Direito de Autor.

Poderá também o mencionado Centro encarregar-se de colecionar informações úteis no que diz respeito à proteção legal e econômica, a bem dos próprios autores e de suas obras, assim como em benefício da cultura, e, ao mesmo tempo, estará pronto para prestar ajuda nesses setores.

6. Estudar e comparar as legislações vigentes, a fim de preparar seu aperfeiçoamento e coordenação, especialmente as que tratam aspectos econômicos e tecnológicos do Direito de Autor nas técnicas modernas de comunicação.

7. Propiciar a criação de Institutos de Direito de Autor em cada país da América, onde já não existam outros com finalidade análoga, e, quando necessário, atuar como órgão de relacionamento entre eles no Continente Americano.

8. A publicação de um Boletim ou Revista especializada relativa a assuntos de interesse para seus membros.

9. Desenvolver outras atividades similares que o Instituo considera necessárias para a consecução de suas finalidades.

Um duplo apelo.

Os dados estão lançados.

O Instituto Interamericano de Direito de Autor aqui está, inteiro, tal como foi estruturado por Natalio Chediak, tão merecidamente eleito seu Secretário.

Como seu idealizador, ele espera que a leitura serena e imparcial dos propósitos do Instituto encontre acolhida imediata por parte dos advogados, juristas, sociedades de autores, seus assessores jurídicos e demais associações ou centros científicos do Continente interessados na matéria.

Nós esperamos muito mais do que isso. 
Esperamos que todo autor, todo artista, todo cientísta americano, todo homem de boa vontade, de inteligência, de cultura e de ação, todo aquele que preza a mais lídima, a mais bela, a mais elevada das manifestações laborativas, se compenetre de que não pode furtar-se a uma colaboração que brota espontânea do próprio sentimento de amor para com as coisas lindas da vida, não regateando o seu apoio a tão grande tarefa de prestigiar a defesa coordenada do Direito de Autor no Continente Americano, no desvelo pelos bens supremos do homem, dessas centelhas sublimes de que foi dotado, e que o separam das bestas e das pedras: a inteligência e a sensibilidade.

Quiseram os membros do Comité v, da Seção c, da xvin Conferência da Federação Interamericana de Advogados, ao Criarem o Instituto, em seu descortino, conceder à Faculdade de Direito da Universidade de São Paulo o privilégio de ser a sua sede, por ter sido a primeira a instalar, em sua Pós-Graduação, um curso regular de Direito de Autor, e, em sua generosidade, a mim, por ser seu Professor, a desmedida honraria de ser seu Presidente.

Nessa qualidade faço, desta tribuna excelsa, um duplo apelo.

Aos meus compatriotas, concitando-os a que mostrem quanto sabemos dar valor a essa prerrogativa, que tão extraordinariamente aumenta nossas responsabilidades.

Precisamos, para isso, prepararmo-nos jurídica, psicológica e até mesmo emocionalmente para colocarmos em movimento tão valioso aparelho, vencendo resistências, quebrando tabus, realizando reformas, divulgando e popularizando o Direito de Autor, racionalizando e barateando sua aplicação através de uma arrecadação única, uniforme, justa, centralizada, e tanto quanto possível exata para uma distribuição absolutamente imparcial e acima de qualquer suspeita. 
O que de resto é inelutável no momento em que o Governo Federal, através de seu Ministro da Justiça, Prof. Alfredo Buzaid, mostra o seu empenho, encaminhando uma solução.

Aos americanos em geral, para que nos irmanemos na promoção e no progresso do Direito de Autor em termos continentais, dando impulso e prestígio às forças mais significativas da nossa civilização.

Que seja o Instituto a primeira luz a se acender contra toda a escuridão opressiva que envolve o Direito de Autor.

Mas que não permaneça a única: que outros institutos regionais se constituam ou se afirmem em cada país do nosso Continente, e que irradiando de toda parte: de Washington, do México, de Buenos Aires, de Montevidéu, de Santiago, de Quito, de Lima, de Assunción, de La Paz e de tantas outras capitais, vençam as trevas e façam resplandecer, finalmente, um dia, o Direito de Autor em toda claridade!

Trabalho para um século?

E verdade!

Pois então, senhores, congreguemos logo nossos esforços, pois um século começa neste instante e passa depressa! 